\title{
PROSTATIC LESIONS: HISTOPATHOLOGICAL STUDY IN A TERTIARY CARE HOSPITAL
}

\author{
Bhatta $\mathrm{S}^{1^{*}}$, Hirachan $\mathrm{S}^{2}$ \\ ${ }^{1}$ Department of Pathology, KIST Medical College \\ ${ }^{2}$ Department of Surgery, KIST Medical College \\ "Corresponding Author:
}

Dr. Sushama Bhatta, Associate Professor, Department of Pathology, KIST Medical College, Lalitpur, Nepal. E-mail: sushmabhatta@gmail.com

\section{ABSTRACT}

Background: Prostatic lesions like Nodular hyperplasia of prostate, inflammation and carcinoma are common causes of morbidity and mortality in males. The incidence of these lesions increases with age. This study was conducted with the objective of evaluating histopathological pattern of prostatic lesions.

Methods: This was a retrospective study conducted at KIST Medical College from Jan 2014 to Jan 2018. The study included ninety six prostatic specimens received in department of pathology. Hematoxylin and Eosin stained slides were retrieved and reviewed. The specimens and slides were analyzed according to type of specimen, age of patient, histopathological pattern and final diagnosis. Results were analyzed using Statistical Package for Social Science (SPSS, version 21) for Windows. Independent $t$ test was used to correlate the mean age between patients with benign and malignant lesions. $\mathrm{P}$ value less than 0.05 was considered as statistically significant.

Results: The most common benign lesion was nodular hyperplasia of prostate $86(89.58 \%)$. Malignant lesions comprised $8(8.34 \%)$ cases of all prostatic lesions. All the cases of prostate carcinoma were adenocarcinoma. The most frequent Gleason score was 9. Mean age for benign and malignant lesions were $69.6 \pm 8.1$ years and $72.9 \pm 5.2$ years respectively. There was no significant difference in the mean age between patients with benign and malignant lesions ( $p$ value 0.27 ).

Conclusion: Benign lesions of prostate are more common than malignant lesions. Histopathological examination of prostate specimens have important role in diagnosing various benign and malignant lesions, especially to rule out incidental carcinoma.

Key words: Prostate, lesions, Nodular hyperplasia of prostate, prostate carcinoma

\section{INTRODUCTION}

Prostate is a retroperitoneal organ which is histologically composed of glands and fibromuscular stroma. Growth and survival of prostatic cells is maintained by testicular androgens. Nodular hyperplasia of prostate and carcinoma of prostate are two most common lesions affecting 
prostate gland. Most hyperplasia arise in transitional zone of prostate whereas carcinoma originate in peripheral zone. ${ }^{1}$

The incidence of nodular hyperplasia of prostate increases with age with $8 \%$ occuring during fourth decade, $50 \%$ in the fifth decade and upto $75 \%$ in the eighth decade. ${ }^{2}$ Prostatitis is the inflammation of prostate which is divided into acute, chronic and granulomatous prostatitis. Chronic prostatitis involves periglandular infiltration of lymphocytes, plasma cells and histiocytes along with interstitial fibrosis. It is usually associated with nodular hyperplasia of prostate and occurs in approximately $10-15 \%$ of men. ${ }^{3}$

High grade prostatic intraepithelial neoplasia (HGPIN) is a premalignant condition of prostatic adenocarcinoma. ${ }^{4}$ Prostate carcinoma is the second most frequently diagnosed cancer and sixth leading cause of cancer death in males. ${ }^{5}$ The objective of this study was to determine the age distribution of various prostatic lesions, to evaluate histopathological pattern of prostatic lesions and to analyze adenocarcinoma of prostate according to Gleason system.

\section{MATERIALS AND METHODS}

This was a retrospective study conducted in the departments of pathology and surgery at KIST Medical College from Jan 2014 to Jan 2018. Transurethral resection of prostate (TURP) and prostatectomy specimens received in the pathology department were included in the study. Inadequate biopsy, Tru cut biopsy and poorly preserved specimens were excluded from the study. The specimen received were fixed in $10 \%$ formalin, cut into 4-6 $\mu$ sections and stained with routine Hematoxylin and Eosin stain. Histopathological slides of the specimens were retrieved and reviewed under light microscope. The findings were analyzed as type of specimen, age of patient, histopathological pattern and diagnosis. The tumors were classified according to 2016 WHO classification and histological grading was done using modified Gleason system. ${ }^{6}$

Data were entered in Microsoft excel sheet and analyzed using Statistical Package for Social Science (SPSS, version 21) for Windows. Independent $t$ test was used to correlate the mean age between patients with benign and malignant lesions. $\mathrm{P}$ value less than 0.05 was considered as statistically significant.

\section{RESULTS}

A total of 96 specimens were received in pathology department, out of which 85 (88.54\%) were TURP and 11(11.46\%) were prostatectomy specimens Fig 1 . Most of the prostatic lesions were benign $86(89.58 \%)$ cases. Malignant lesions comprised $8(8.34 \%)$ cases of all prostatic lesions. HGPIN was observed in 2(2.08\%) cases. Majority of the benign lesions were common in the age group of 61-70 years. Mean age for benign lesions was 69.6 \pm 8.1 years (Age range 51-88 years). Malignant lesions were common in the age group of 71-80 years. The mean age for malignant lesions was $72.9 \pm 5.2$ years (Age range 68-83 years). There was no significant difference in the mean age between patients with benign and malignant lesions ( $p$ value 0.27). Age wise distribution of prostatic lesions is shown in (Table 1). 
Table 1. Age wise distribution of prostatic lesions

\begin{tabular}{|c|c|c|c|c|}
\hline $\begin{array}{ll}\text { Age } & \text { group } \\
\text { (years) }\end{array}$ & Benign & HGPIN & Malignant & Total $(\%)$ \\
\hline $51-60$ & 10 & 1 & 1 & $12(12.5)$ \\
\hline 61-70 & 40 & 1 & 2 & 43 (44.79) \\
\hline 71-80 & 30 & 0 & 4 & $34(35.41)$ \\
\hline $81-90$ & 6 & 0 & 1 & $7(7.3)$ \\
\hline Total (\%) & $86(89.58)$ & $2(2.08)$ & $8(8.34)$ & $96(100)$ \\
\hline
\end{tabular}

Table 2. Histopathological diagnosis of prostatic lesions

\begin{tabular}{lll}
\hline Histopathological diagnosis & No of cases & Percentage (\%) \\
\hline Nodular hyperplasia of prostate & 62 & 64.58 \\
Nodular hyperplasia of prostate with prostatitis & 24 & 25 \\
HGPIN & 2 & 2.08 \\
Adenocarcinoma of prostate & 8 & 8.34 \\
Total & 96 & 100 \\
\hline
\end{tabular}

Table 3. Gleason score in malignant prostatic lesions

\begin{tabular}{lll}
\hline Gleason score & Number of cases & Percentage $(\%)$ \\
\hline $\mathbf{6}$ & 1 & 12.5 \\
$\mathbf{7}$ & 2 & 25 \\
$\mathbf{8}$ & 2 & 25 \\
$\mathbf{9}$ & 3 & 37.5 \\
\hline
\end{tabular}




\section{Original Article}

\begin{tabular}{|lll|}
\hline Total & 100 & \\
\hline & & \\
\hline & & D TURP \\
& $88.54 \%$ & Prostatectomy \\
\hline
\end{tabular}

Fig 1. Type of specimens in prostatic lesions
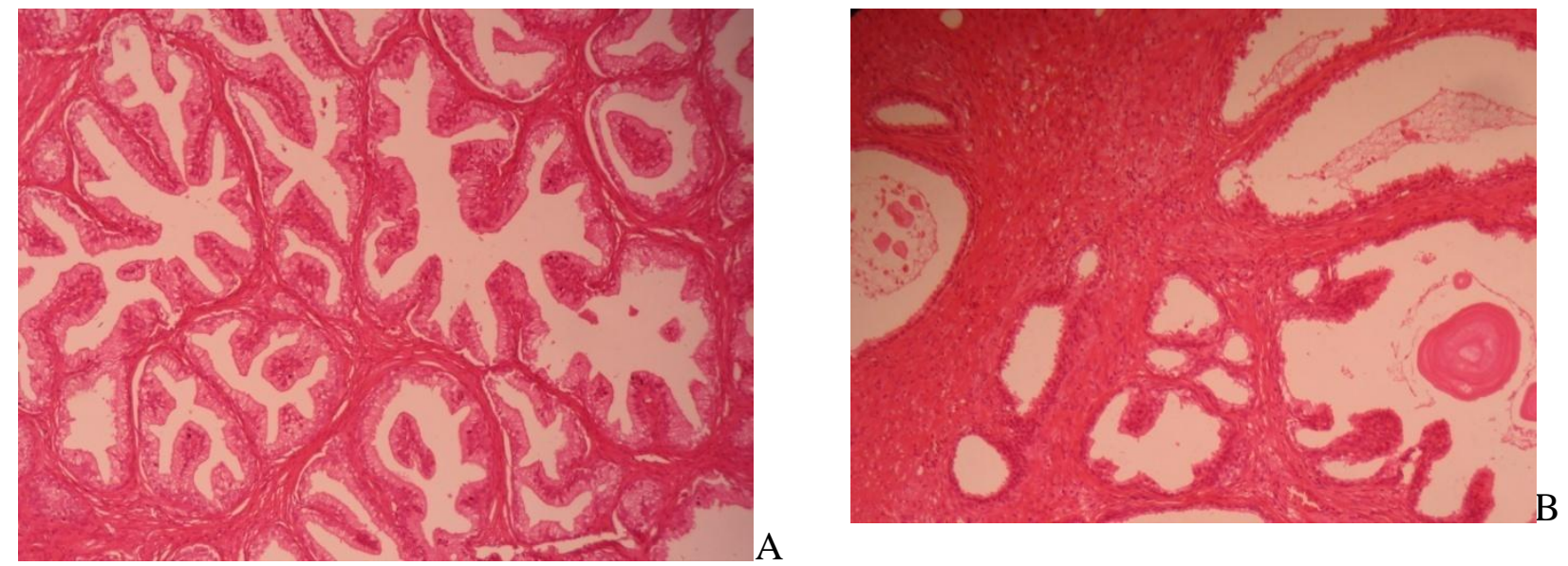

Fig 2.Nodular hyperplasia of prostate showing hyperplasia of glands with papillary foldings (A), Mixed glandular and stromal hyperplasia. Lumen shows corpora amylacea (B) H and E X100 


\section{Original Article}
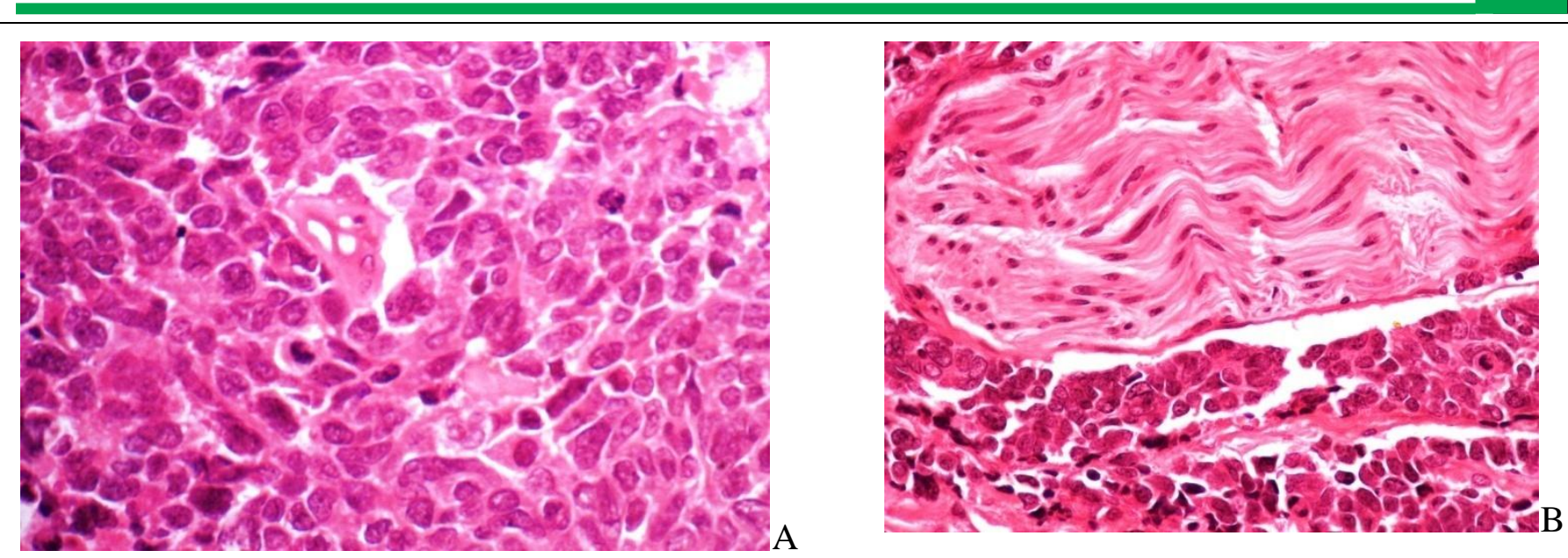

Fig 3.Carcinoma of prostate with tumor cells arranged in diffuse sheets (A) and perineural invasion (B) $\mathrm{H}$ and $\mathrm{E} \times \mathbf{x} 40$

Nodular hyperplasia of prostate was the most frequent histo-pathological diagnosis seen in 86 $(89.58 \%$ ) patients (Table 2). 24(25\%) cases of nodular hyperplasia of prostate had associated prostatitis, out of which 22 cases were of chronic non-specific prostatitis and two cases were of acute prostatitis. Microscopic findings associated with nodular hyperplasia of prostate comprised hyperplasia of both epithelial and stromal cells with cystically dilated glands and corpora amylacea (Fig 2). All 8 cases of prostatic carcinoma were adenocarcinoma. Out of 8 cases of prostate carcinoma, 7 were incidental carcinoma which accounted for $7.29 \%$ of all prostatic lesions. Gleason score 9 was the commonest score seen in 3 out of 8 cases (37.5\%) (Table 3, Fig 3).

\section{DISCUSSION}

Prostate is involved by various pathological conditions including nodular hyperplasia of prostate, inflammation, premalignant and malignant lesions. Although tools such as trans-rectal ultrasound, prostate specific antigen (PSA) are used for screening of prostate cancer, biopsy still remains the gold standard for final diagnosis. ${ }^{7}$ In our study most of the specimens received were TURP (88.54\%), which was similar to other studies. ${ }^{8,9}$ This could be due to the fact that TURP is a preferred surgery for nodular hyperplasia of prostate as it is a simple procedure with fewer complications. Majority of the prostatic lesions were benign $(89.58 \%)$ followed by carcinoma $(8.34 \%)$ and HGPIN $(2.08 \%)$ in the present study. Deshmukh BD et al ${ }^{10}$ have found $91.6 \%$ cases of benign lesions, $7.96 \%$ adenocarcinoma and $0.44 \%$ HGPIN in their study.

Hormones such as androgen and advanced age are the factors associated with prostatic lesions. ${ }^{1}$ In the present study mean age for benign and malignant lesions were $69.6 \pm 8.1$ years and $72.9 \pm$ 5.2 years respectively. There was no significant difference in the mean age between patients with benign and malignant lesions ( $p$ value 0.27). This finding is in agreement with the study by Garg $\mathrm{M}$ et al ${ }^{7}$. Benign lesions were common in the age group of 61-70 years whereas malignant lesions were common in the age group of 71-80 years which is in concordance with other studies. ${ }^{8,11,12}$ Among the benign lesions nodular hyperplasia of prostate was the most frequent 
histo-pathological diagnosis in our study accounting for $89.58 \%$ cases. Bal et al ${ }^{13}$ and Dawam et a ${ }^{14}$ observed Nodular hyperplasia of prostate in $87 \%$ and $86 \%$ cases respectively which is similar to our study. Nodular hyperplasia of prostate occurs due to proliferation of epithelial cells and fibro muscular stromal cells. Hyperplastic glands form papillary infoldings. Some of the glands are cystically dilated and contain thick secretions in their lumen called corpora amylacea. The glands are lined with inner columnar and outer cuboidal or flattened epithelium. Basal cell layer is seen above the basement membrane. ${ }^{2}$ In the present study nodular hyperplasia of prostate showed proliferation of both epithelial and stromal components.

Prostatitis was associated with $24(25 \%)$ cases of nodular hyperplasia of prostate in the present study, out of which 22 cases were of chronic nonspecific prostatitis and two cases were of acute prostatitis. No cases of granulomatous prostatitis were found in our study. Patel SK et al ${ }^{11}$ and Josephine $\mathrm{A}^{15}$ have reported chronic prostatitis associated with nodular hyperplasia of prostate in $26.78 \%$ and $25.31 \%$ cases respectively. Sharma A et al ${ }^{12}$ found prostatitis in $33.06 \%$ cases of Nodular hyperplasia of prostate out of which $86.42 \%$ cases were chronic non-specific prostatitis, $9.88 \%$ were acute prostatitis and $3.7 \%$ were granulomatous prostatitis. Squamous metaplasia associated with nodular hyperplasia of prostate was seen in 1(1.04\%) case in the current study. Metaplasia in nodular hyperplasia of prostate is usually secondary to inflammation or injury. Garg M et al ${ }^{7}$ and Abdollahi A et al ${ }^{16}$ observed squamous metaplasia in $0.8 \%$ and $0.3 \%$ cases in their studies.

HGPIN is a precursor lesion of prostatic carcinoma. The finding of HGPIN along with elevated serum PSA is an indication of repeat biopsy and follow up. ${ }^{4,10,17}$ In our study $2(2.08 \%)$ cases showed HGPIN similar to the study by Sharma A et al ${ }^{12}$ who have found $2.04 \%$ HGPIN in their studies. Our study showed $8(8.34 \%)$ of prostate carcinoma which was similar to other studies. ${ }^{10,18}$ All the prostate carcinoma were histologically adenocarcinoma in the present study. This finding was in agreement with other studies. ${ }^{19,20}$ Incidental carcinoma is carcinoma detected on histo-pathological examination of prostatic tissue which is removed with the clinical diagnosis of benign lesion. In our study 7 out of 8 carcinoma were incidental carcinoma which accounts for $7.29 \%$ of all cases. Sharma et al ${ }^{12}$ found all prostate carcinoma as incidental carcinoma in their study. Dellavedova $\mathrm{T}$ et al ${ }^{21}$ reviewed 100 TURP specimens and found incidental cancer detection rate of $7 \%$ similar to our study. Adenocarcinoma were graded according to modified Gleason system ${ }^{6}$ which was based on degree of glandular differentiation at low power examination. The Gleason grading correlates with tumor aggressiveness, tumor volume and prognosis. ${ }^{15}$ Tumors with Gleason score 8-10 have advanced cancers with poor prognosis. ${ }^{1}$ Most common grade was grade 4 and the most predominant Gleason score was 9 in our study which indicated poor prognosis. Gleason score of 9 was seen in 3 out of 8 cases (37.5\%). Similar to our study Deshmukh BD et al ${ }^{10}$ found Gleason score 9 in $33.33 \%$ cases. Bhat $\mathrm{S}$ et al ${ }^{18}$ observed $56.16 \%$ cases of adenocarcinoma with Gleason score of $8-9$. In a study by Kasliwal $\mathrm{N}$ et al ${ }^{8}$ Gleason score 8 was the most common score seen in $47.4 \%$ cases.

Perineural invasion is a pathognomic feature of prostate cancer if there is circumferential or intraneural invasion by the tumor cells. ${ }^{22}$ Perineural invasion was seen in $3(37.5 \%)$ cases of all prostatic carcinoma in the present study. Various authors have reported perineural invasion in prostate carcinoma ranging from 24- $42 \% .^{7,8,11}$ In our study among three cases of adenocarcinoma with perineural invasion, two cases had Gleason score 9 and one case had 
Gleason score 7. Perineural invasion was common in carcinoma with high Gleason score similar to other study. ${ }^{11}$

\section{CONCLUSION}

TURP specimens were the most common type of specimen received for prostatic lesions. Predominant benign lesion was nodular hyperplasia of prostate. All cases of prostate carcinoma were adenocarcinoma and majority were incidental carcinoma. Perineural invasion was commonly seen with high Gleason score. Histopathological examination of prostatic specimens have important role in the diagnosis and management of various prostatic lesions.

\section{CONFLICT OF INTEREST}

None declared.

\section{REFERENCES}

1. Epstein JI. The lower urinary tract and male genital system. In: Kumar V, Abbas AK, Fausto N, Aster JC, editors. Robbins and Cotran Pathologic Basis of Disease. $8^{\text {th }}$ ed. New Delhi: Elsevier, 2010:P993-1002.

2. Rosai J. Male reproductive system. In: Rosai J, editor. Rosai and Ackerman's Surgical Pathology. 10 $0^{\text {th }}$ ed. New Delhi: Elsevier, 2011:1287-1333.

3. Harik LR, O'Toole KM. Nonneoplastic lesions of the prostate and bladder. Arch Pathol Lab Med. 2012;136:721-734.

4. Chandanwale S, Jadhav PS, Anwekar SC, Kumar H, Buch AC, Chaudhari US, et al. Clinico-pathological study of benign and malignant lesions of prostate. IJPBS. 2013;3:162-178.

5. Dabir PD, Ottosen P, Hoyer S, Hamilton-Dutoit S. Comparative analysis of three-and two-antibody cocktails to AMACR and basal cell markers for the immunohistochemical diagnosis of prostate carcinoma. DiagnPathol. 2012;7: 81.

6. Humphrey PA,Moch H, CubillaAL ,Ulbright TM, Reuter VE. The 2016 WHO Classification of Tumours of the Urinary System and Male Genital Organs-Part B: Prostate and Bladder Tumours. Eur Urol. 2016;70:106-119.

7. Garg M, Kaur G, Malhotra V, Garg R. Histopathological spectrum of 364 prostatic specimens including immunohistochemistry with special reference to grey zone lesions. Prostate Intl. 2013;1:146-151.

8. Kasliwal N. Pattern of prostatic disease- a histopathological study with clinical correlation. EJPMR. 2016; 3:589-97.

9. Shakya G, Malla S, Shakya KN. Salient and co-morbid features in benign prostatic hyperplasia: A histopathological study of the prostate. Kathmandu Univ Med J.2003;2:104-109.

10. Deshmukh BD, Ramteerthakar NA, Sulhyan KR. Histopathological study of lesions of prostate- A five year study. Int J Health Sci Res. 2014;4:1-9.

11. Patel SK, Surti HB. Analysis of prostatic biopsies in a tertiary care hospital in correlation with prostate-specific antigen levels: A clinicopathological study. Int J Med Sci Public Health. 2017; 6:842-846. 
12. Sharma A, Sharma M, Gandhi S, Khajuria A, Goswami KC. Histomorphological spectrum of prostatic lesions: a retrospective analysis of transurethral resection of prostate specimens. Int J Res Med Sci. 2017;5: 2373-2378.

13. Bal MS, Kanwal S, Goyal AK, Singla N. Prostatic lesions in surgical biopsy specimens. JK Pract. 2011;16:33-34.

14. Dawam D, Rafindadi AH, Kalayi GD. Benign prostatic hyperplasia and prostate carcinoma in native Africans. BJU Int. 2000;85:1074-1077.

15. Josephine A. Clinicopathological study of prostatic biopsies. J ClinDiagn Res. 2014;8:46.

16. Abdollahi A, Ayati M. Frequency and outcome of metaplasia in needle biopsies of prostate and its relation with clinical findings. Urol J. 2009;6:109-113.

17. Epstein JI. Precursor lesions to prostatic adenocarcinoma. Virchows Arch. 2009;454:116.

18. Bhat S, Chaudhri S, Bhat P, Hatwal D. Histopathologicl study of prostatic diseases in Garhwal region. Int J Sci Stud. 2015;3:136-140.

19. Begum Z, Attar AH, Tengli MB, Ahmed MM. Study of various histopathological patterns in TURP specimens and incidental detection of carcinoma prostate. Indian $J$ Pathol and Oncol.2015;2:303-308.

20. Mohammed AZ, Nawana EJC, Anjorin AS. Histopathological pattern of prostatic diseases in Nigerians. African Journal of Urology. 2005;11:33-38.

21. Dellavedova T, Ponzano R, Racca L, Minuzzi F, Dominguez M. Prostate cancer as incidental finding in transurethral resection. Arch Esp Urol. 2010;63:855-861.

22. Velickovic L, Katic V, TasicDimov D, Dordevic B, Zivkovic V, Zivkovic S, et al. Morphologic criteria for the diagnosis of prostatic adenocarcinoma in needle biopsy specimens. Arch Oncol. 2004;12:54-55. 